\title{
Heat transfer performance evaluation and prediction of correlation for turbulent flow through a tube with helical tape inserts at higher Reynolds number
}

\author{
Muhammad Mostafa Kamal Bhuiya ${ }^{1,2} \cdot$ M. S. U. Chowdhury ${ }^{2,3} \cdot$ J. U. Ahamed ${ }^{2}$. \\ A. K. Azad ${ }^{1}$
}

Received: 24 August 2014 / Accepted: 16 July 2015 / Published online: 25 July 2015

(C) Springer-Verlag Berlin Heidelberg 2015

\begin{abstract}
An experimental investigation was accomplished to evaluate the performance of heat transfer for turbulent flow through a tube with helical tape inserts. The mild steel helical tape inserts with different twist ratios of 1.88, 3.13, 4.69, 6.41 and 7.81 were used in the flow field. Heat transfer and pressure drop data were prompted for a wide range of Reynolds number from 7200 to 50,000. The experimental results indicated that the Nusselt number, friction factor and thermal performance factor were increased with decreasing twist ratio. The results also showed that helical tape inserts of different geometries in a circular tube enhanced the heat transfer rate significantly with corresponding increase in friction factor. Nusselt number and friction factor for the tube with inserts were found to be increased up to 260 and $285 \%$, respectively, than those over the plain tube values at the comparable Reynolds number. The heat transfer performance was evaluated and found to be $44 \%$ higher compared to the plain tube based on the constant blower power. Finally, new correlations were proposed for the twist ratios ranging from 1.88 to 7.81 for predicting the heat transfer, friction factor and thermal performance factor for turbulent flow through a circular tube fitted with helical tape inserts.
\end{abstract}

Muhammad Mostafa Kamal Bhuiya

mkamalcuet@yahoo.com; m.bhuiya@cqu.edu.au

1 School of Engineering and Technology, Central Queensland University (CQUniversity), Rockhampton, Queensland 4702, Australia

2 Department of Mechanical Engineering, Chittagong University of Engineering and Technology (CUET), Chittagong 4349, Bangladesh

3 School of Engineering and Information Technology, The University of New South Wales, Canberra, ACT 2600, Australia

\section{List of symbols}

$A_{x} \quad$ Cross sectional area of test section $\left(\mathrm{m}^{2}\right)$

$C_{p} \quad$ Specific heat at constant pressure $(\mathrm{J} / \mathrm{kg} \mathrm{K})$

$D_{i} \quad$ Tube inside diameter $(\mathrm{m})$

$D_{o} \quad$ Tube outer diameter (m)

$f \quad$ Friction factor, dimensionless

$f_{p} \quad$ Predicted friction factor, dimensionless

$h \quad$ Convective heat transfer coefficient $\left(\mathrm{W} / \mathrm{m}^{2} \mathrm{~K}\right)$

$h_{x} \quad$ Local convective heat transfer co-efficient $\left(\mathrm{W} / \mathrm{m}^{2} \mathrm{~K}\right)$

I Current [ampere]

$k \quad$ Thermal conductivity (W/m K)

$L \quad$ Tube length (m)

$\dot{m} \quad$ Mass flow rate $(\mathrm{kg} / \mathrm{s})$

$P \quad$ Pitch length (m)

$\Delta P \quad$ Pressure drop along the length of the tube $\left(\mathrm{N} / \mathrm{m}^{2}\right)$

$Q \quad$ Heat rate absorbed by the fluid (W)

$q \quad$ Heat flux $\left(\mathrm{W} / \mathrm{m}^{2}\right)$

$Q_{\text {tloss }} \quad$ Total heat rate loss (W)

$Q_{t} \quad$ Generated total heat rate (W)

$Q_{a} \quad$ Actual heat rate supplied (W)

$T_{i} \quad$ Inlet temperature (K)

$T_{o} \quad$ Outlet temperature (K)

$\bar{T}_{b} \quad$ Mean bulk temperature $(\mathrm{K})$

$\bar{T}_{w} \quad$ Mean wall temperature (K)

$T_{b x} \quad$ Local bulk fluid temperature (K)

$T_{w x} \quad$ Local wall temperature (K)

$V \quad$ Mean velocity in the test section $(\mathrm{m} / \mathrm{s})$ dimensionless

$\dot{V} \quad$ Mass flow flux $\left(\mathrm{kg} / \mathrm{s} . \mathrm{m}^{2}\right)$

$V_{i} \quad$ Mean velocity at inlet section $(\mathrm{m} / \mathrm{s})$

$V_{v} \quad$ Voltage (volt)

$W \quad$ Wetted perimeter (m)

$W_{d} \quad$ Tape width (m)

$X \quad$ Axial distance (m) 
y Twist ratio, dimensionless

\section{Greek symbols}

$\eta \quad$ Thermal performance factor, dimensionless

$\eta_{p} \quad$ Predicted thermal performance factor, dimensionless

$\rho \quad$ Density $\left(\mathrm{kg} / \mathrm{m}^{3}\right)$

\begin{tabular}{ll}
\multicolumn{2}{l}{ Subscripts } \\
b & Bulk \\
i & Inlet \\
o & Outlet \\
p & Tape inserts \\
s & Plain \\
w & Wall \\
X & Local
\end{tabular}

\section{Dimensionless numbers}

$\mathrm{Nu} \quad$ Nusselt number, dimensionless

$N u_{p} \quad$ Predicted Nusselt number, dimensionless

$N u_{x} \quad$ Local Nusselt number, dimensionless

$\mathrm{Pr} \quad$ Prandtl number, dimensionless

Re Reynolds number, dimensionless

$R e_{p} \quad$ Equivalent Reynolds number for the tube with tape inserts, dimensionless

$R e_{s} \quad$ Equivalent Reynolds number for plain tube, dimensionless

\section{Introduction}

Heat transfer augmentation techniques are frequently used in heat exchanger systems in order to enhance heat transfer and improve the thermal performance. Turbulent generators with different geometrical configurations have been used as one of the passive heat transfer enhancement techniques and are widely used in several heat transfer applications, for example, heat recovery processes, air conditioning and refrigeration systems, cooling of modern electronic appliances, chemical reactors, food and dairy processes. Therefore, the using of high performance heat exchangers is very important for saving energy. Several methods are applied to improve the thermal performance of heat transfer devices such as treated surfaces, rough surfaces as well as incorporations of inserts (such as turbulators and swirl flow devices). Among the passive techniques, insertion of swirl generator is one of the most promising techniques. The swirl generator caused recirculation of an existing axial flow, which leads to an improvement of fluid mixing and thus obtained an efficient reduction of the thickness of boundary layer $[1,2]$.

Extensive studies have been performed from the beginning of the twentieth century to determine the heat transfer characteristics inside the tubes. Sarkar et al. [3] experimentally studied the heat transfer enhancement and friction factor characteristics in turbulent flow through a tube with wire-coil inserts. The results showed that the heat transfer coefficient for the tube with wire-coil inserts increased with corresponding increase in friction factor in comparison to that of the plain tube at a comparable Reynolds number. Naphon [4] studied the effect of coil wire inserts on heat transfer enhancement and pressure drop of the horizontal concentric plain tubes. The results indicated that the coil wire inserts have significant influence on the enhancement of heat transfer. The heat transfer coefficient was increased with the decrease of coil pitch. Promvonge [5] investigated the influences of the insertion of coiled-wires in combination with a snail type swirl generator mounted at the tube entrance on heat transfer and friction factor characteristics through a circular tube under uniform heat flux condition for the turbulent flow regime. It was shown that the snail entry with the coiled square-wire provided the highest heat transfer rate than the others under the same operating conditions. Gunes et al. [6] assessed the effect of coiled wire inserts on heat transfer and pressure drop characteristics with three different pitch ratios in the range of Reynolds number from 3500 to 27,000 under uniform heat flux conditions. The use of coiled wire inserts at lower pitch ratios led to a significant enhancement of heat transfer with corresponding increase in pressure drop over the smooth tube.

Among many techniques investigated for augmentation of heat transfer rates inside circular tubes, a wide range of inserts has been utilized. A number of experimental studies have been reported to investigate the effects of various inserts. Promvonge [7] investigated the influences of insertion of wire coils in conjunction with twisted tapes on heat transfer and turbulent flow friction characteristics through a circular tube with different coil pitch and twist ratios under uniform heat flux condition. It was reported that the present of wire coils together with twisted tapes led to a double increase in heat transfer over the use of wire coil/twisted tape alone. Under the same operating conditions, the combined twisted tape and wire coil with a smaller twist and coil pitch ratios provided the higher heat transfer rate than those with the other ones causing an increase in higher pressure drop. Eiamsa-ard et al. [8] investigated the heat transfer and fluid friction characteristics in a double pipe heat exchanger fitted with regularly spaced twisted tape elements. The results showed that the heat transfer coefficient as well as friction factor increased with the decrease of twist ratio. In addition, the use of small values of space ratio yielded the higher heat transfer than that of the lager space ratio. Naphon [9] experimentally studied the heat transfer and pressure drop characteristics in the horizontal double pipes with twisted tape insert. It was shown that the twisted tape insert had a significant effect on enhancing 
heat transfer rate, while the pressure drop was increased. It was also found that the heat transfer rate at lower twist ratio was higher than those from higher ones across the range of Reynolds number. The experimental investigations of heat transfer and friction factor characteristics of a square duct fitted with twisted tapes of different twist ratios at nearly uniform wall temperature conditions were reported by Patil and Vijaybabu [10]. It was obtained that the Nusselt number and friction factor value was increased with decreasing twist ratio. The maximum heat transfer enhancement was observed for a minimum twist ratio. Zohir [11] investigated the heat transfer and pressure drop characteristics for turbulent airflow through an axisymmetric sudden expansion pipe equipped with propeller swirl generator for the Reynolds number ranging from 10,000 to 41,000 under uniform heat flux condition. The results indicated that inserting the propeller at downstream of the tube provided noteworthy improvement of the heat transfer rate higher than inserting the propeller at upstream of the tube. The higher increase in pressure drop was obtained at upstream of the propeller than the downstream swirler.

Eiamsa-ard et al. [12] presented the experimental results of mean Nusselt number, friction factor and enhancement efficiency through a circular tube with short-length twisted tape inserts of several tape length ratios mounted at the entry of the test section under uniform heat flux condition. It was indicated that the short length twisted tapes performed lower results of heat transfer, friction factor as well as the enhancement efficiency than the full length tape insert. In addition, the tube with short length twisted tape inserts yielded higher heat transfer rates with corresponding increase in friction factor at lower tape length ratios. Eiamsa-ard et al. [13] studied the influences of twincounter/co-twisted tapes on heat transfer, friction factor and thermal enhancement index with four different twist ratios $(2.5,3.0,3.5,4.0)$ in the turbulent flow regime under uniform heat flux conditions. The Nusselt number, friction factor and thermal performance factor increased with decreasing twist ratio. It was also clear from the results that the twin-counter twisted tapes were more efficient than the twin co-twisted tapes for heat transfer enhancement.

Eiamsa-ard and Promvonge [14] presented the results of turbulent heat transfer and flow friction characteristics in a circular tube equipped with typical twisted tapes and alternate clockwise and counterclockwise twisted tapes with different twist ratios $(3.0,4.0,5.0)$ and twist angles $\left(30^{\circ}, 60^{\circ}, 90^{\circ}\right)$. It was obtained that the alternate clockwise and counterclockwise twisted tapes provided the higher heat transfer rate, friction factor and thermal performance factor than the typical twisted tapes in similar operating conditions. It was also shown that the heat transfer rate of the alternate clockwise and counter clockwise twisted tapes was increased with the decrease of twist ratio and the increase of twist angles. Heat transfer, friction factor and thermal performance characteristics of $\mathrm{CuO} /$ water nanofluid employed in a circular tube equipped with modified twisted tape with alternate axis at a constant twist ratio was investigated by Wongcharee and Eiamsa-ard [15]. The use of nanofluid with modified twisted tape with alternate axis provided significantly higher heat transfer and thermal performance than that of nanofluid with typical twisted tape with corresponding increase in friction factor.

The effects of twisted tapes with alternate axes and wings in three different shapes including triangle, rectangle and trapezoidal on heat transfer, flow friction and thermal performance characteristics in a circular tube with three different wing-chord ratios $(0.1,0.2$, and 0.3$)$, and at a constant twist ratio in turbulent regime was investigated by Wongcharee and Eiamsa-ard [16]. It was shown from the results that both heat transfer rate and friction factor associated with all twisted tapes were consistently higher than those without twisted tape. It was also illustrated that the Nusselt number, friction factor as well as thermal performance factor given by the tape with alternate axes and trapezoidal wings were higher than those given by the others.

Bhuiya et al. [17] experimentally investigated the heat transfer enhancement and pressure drop characteristics of turbulent flow through a circular tube fitted with twisted wire brush inserts of different twisted wire densities (100, $150,200,250)$. The results indicated that the presence of twisted wire brush inserts led to a significant effect on the enhancement of heat transfer with corresponding increase in friction factor over the plain tube. Eiamsa-ard et al. [18] reported the heat transfer enhancement attributed to helically twisted tapes with different twist as well as pitch ratios for Reynolds number range between 6000 and 20,000 . It was revealed that at similar operating conditions, helically twisted tapes showed the lower Nusselt number as well as friction factor, but higher thermal performance factor than conventional helical tapes. Moreover, heat transfer and friction factor were increased with the decrease of tape twist and helical pitch ratio, while the thermal performance showed the opposite trend.

The utilizing of helical tapes for heat transfer enhancement have been extensively reported. Eiamsa-ard and Promvonge $[19,20]$ assessed the results of the enhancement of heat transfer and pressure drop in a heat exchanger tube fitted with regularly spaced helical tapes and helical screw-tape with/without core-rod inserts. It was found in similar operating conditions, the heat transfer rates provided by the helical screw-tape with core-rod were higher than those given by the tape without cor-rod. In addition, heat transfer rate was increased with decreasing regular spacing. Sivashanmugam and Suresh [21, 22] evaluated the heat transfer enhancement, friction factor and thermal performance characteristics in a circular tube fitted with helical screw-tape as well 
as regularly spaced helical screw-tape inserts for the turbulent flow regime. It was found that the heat transfer coefficient and friction factor was increased with the decrease of twist ratio. Sivashanmugam et al. [23] showed the effect of the right and left helical screw-tape on heat transfer, friction factor and thermal performance factor in tubes for turbulent flow region. The higher heat transfer rate was provided for the tube fitted with right-left helical screw-tape inserts at lower twist ratios. Hasan and Sumathy [24] experimentally studied the potential use of swirl flow generators in enhancing the thermal performance of solar air heaters. The study indicated that the higher heat transfer rates were provided at lower twist ratios. Suresh et al. [25] investigated the thermal performance factor of helical screw-tape inserts with different twist ratios in laminar flow region using $\mathrm{Al}_{2} \mathrm{O}_{3}$ /water and $\mathrm{CuO} /$ water nanofluids through a circular duct with constant heat flux condition. Helical screw-tape inserts of lower twist ratios using $\mathrm{CuO} /$ water nanofluid showed the higher thermal performance factor when compared with the corresponding value using $\mathrm{Al}_{2} \mathrm{O}_{3}$ /water.

From the research works reported on different types of inserts by the different researcher, it could be understood that the swirl flow generators like helical screw-tapes were given greater enhancements in heat transfer compared to other inserts. In the present study, the effect of swirling flow generated by the helical tape inserts on heat transfer performance and friction factor characteristics of turbulent flow through a circular tube was evaluated. The experiments were carried out for a wide range of twist ratios and Reynolds number ranging from 1.88 to 7.81 and 7200 to 50,000 , respectively, using air as the working fluid under uniform heat flux condition. In addition, the empirical correlations of heat transfer, friction factor and thermal performance factor were also developed for predicting the heat transfer, friction factor and thermal performance factor, respectively, based on the experimental data.

In this study, some assumptions were made in order to make easy experiments, comparison and analysis, which created some limitations in the actual results. These were:

1. Inside diameter of the tube $(D)$ was used instead of hydraulic diameter $\left(D_{h}\right)$ in defining Reynolds number $(\mathrm{Re})$, Nusselt number $(\mathrm{Nu})$, and friction factor $(f)$.

2. All the fluid properties were calculated at local bulk temperature $\left(T_{b x}\right)$ and at atmospheric pressure instead of local pressure in the test section which was slightly less than the atmospheric pressure.

3 . The heat transfer was considered only by forced convection from the inside wall of the tube to the fluid. However, there were points of contact between the inserts and the inner wall of the tube. Thus there was the potential for heat transfer to occur through the inserts by conduction. It was not possible to quantify this, also heat was conducted through the ends of the test section to adjacent sections.

\section{Mathematical formulations}

The experimental data were used to calculate the Nusselt number, friction factor and thermal performance factor at different Reynolds numbers in turbulent flow region for both the cases with and without using helical tape inserts.

Mass flow rate was calculated by,

$\dot{m}=\rho A_{x} V_{i}$

where, $\rho$ is the density of air, $A_{x}$ is the cross sectional area of test section and $V_{i}$ is the mean inlet velocity.

In the test section, the velocity of air was obtained from,

$V=\frac{\dot{m}}{\rho_{b} A_{x}}$

where, $\rho_{b}$ is the density at bulk fluid temperature.

The total heat generated by the electrical winding was calculated as,

$Q_{t}=V_{v} I$

where, $V_{v}$ is the voltage supplied and $I$ is the current flow through the windings.

The total heat loss $\left(Q_{\text {tloss }}\right)$ was calculated from the measurements of the wall temperature and the ambient temperature (loss through the insulation, $Q_{\text {convec }}=3-5 \%$ ), the conduction loss $\left(Q_{\text {conduc }}=0.3-0.8 \%\right)$ at the ends of the test section, and the radiation loss $\left(Q_{\text {rad }}=0.2-0.7 \%\right)$ from the tube surface to the ambient and estimated as 3.5-6.5\% of the total heat supplied.

Therefore, actual heat supplied by the electrical winding,

$Q_{a}=Q_{t}-Q_{t l o s s}$

The heat absorbed by the fluid was calculated as,

$Q=\dot{m} C_{p}\left(T_{0}-T_{i}\right)$

where, $C_{p}$ is the specific heat of air, $T_{i}$ and $T_{o}$ are the inlet and outlet temperatures of air, respectively.

And the heat flux was calculated by,

$q=\frac{Q}{\pi D_{i} L}$

where, $D_{i}$ is the diameter and $L$ is the length of the tube.

Local convective heat transfer coefficient was obtained from,

$h_{x}=\frac{q}{\left(T_{w x}-T_{b x}\right)}$

where, $T_{w x}$ and $T_{b x}$ are the local wall and bulk fluid temperatures. 


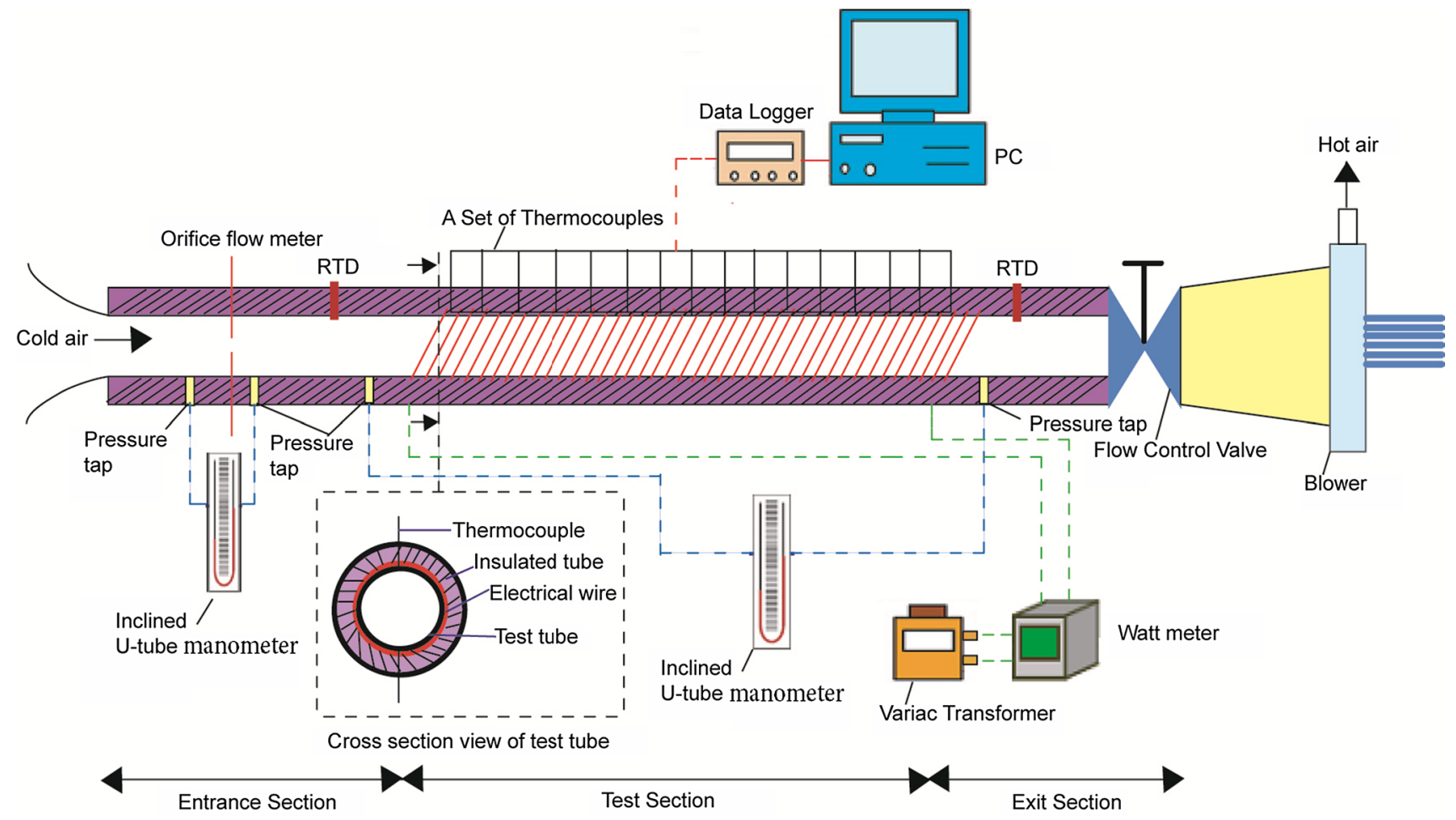

Fig. 1 Schematic diagram of the experimental facility

The bulk fluid temperature was determined by the following energy balance equation,

$T_{b x}=T_{i}+\frac{q W X}{\dot{m} C_{p}}$

where, $W$ is the wetted perimeter and $X$ is the axial distance of the tube.

The local Nusselt number was calculated as,

$N u_{x}=\frac{h_{x} D_{i}}{k}$

where, $k$ is the thermal conductivity of air.

The average heat transfer coefficient was obtained from,

$h=\frac{q}{\left(\bar{T}_{w}-\bar{T}_{b}\right)}$

where, $\bar{T}_{w}$ and $\bar{T}_{b}$ are the mean wall and bulk fluid temperatures.

The average Nusselt number was calculated according to the following way,

$N u=\frac{h D_{i}}{k}$

Friction factor was obtained from,

$f=\frac{\Delta P}{\left(\frac{L}{D_{i}}\right)\left(\rho_{b} \frac{V^{2}}{2}\right)}$ where, $\Delta P$ is the pressure drop along the length of the tube.

\section{Experimental facility}

The experimental facility consisted of an inlet section, a test section, an air supply system (Electric blower) and a heating arrangement (electric heater). The schematic diagram of the experimental facility is shown in Fig. 1. The tube shaped inlet section. $533 \mathrm{~mm}$ long was made as an integral part of the test section to avoid any flow disturbances upstream of the test section and to get fully developed flow in the test section as well. The inlet section shape of the experimental setup was made as per suggestions of Owner and Pankhurst [26] to avoid separation and stratification of the flow.

Geometry of the test section fitted with the helical tape insert with a core-rod and geometric configurations of the tape insert is shown in Fig. 2a, b. The plain tube (test section) was made of brass having $70 \mathrm{~mm}$ inside diameter, $90 \mathrm{~mm}$ outside diameter and $1500 \mathrm{~mm}$ in length. The helical tape inserts of width $64 \mathrm{~mm}$ with various twist ratios, $y=1.88,3.13,4.69,6.41$ and 7.81 were fabricated by winding uniformly over a $15 \mathrm{~mm}$ circular core rod. The twist ratio ' $y$ ' defined as the ratio of length of one twist (pitch, $P$ ) to the diameter of the twist. Nichrome 
Fig. 2 a Geometry of test section fitted with helical tape insert with a core-rod; b Geometric parameters of the helical tape insert
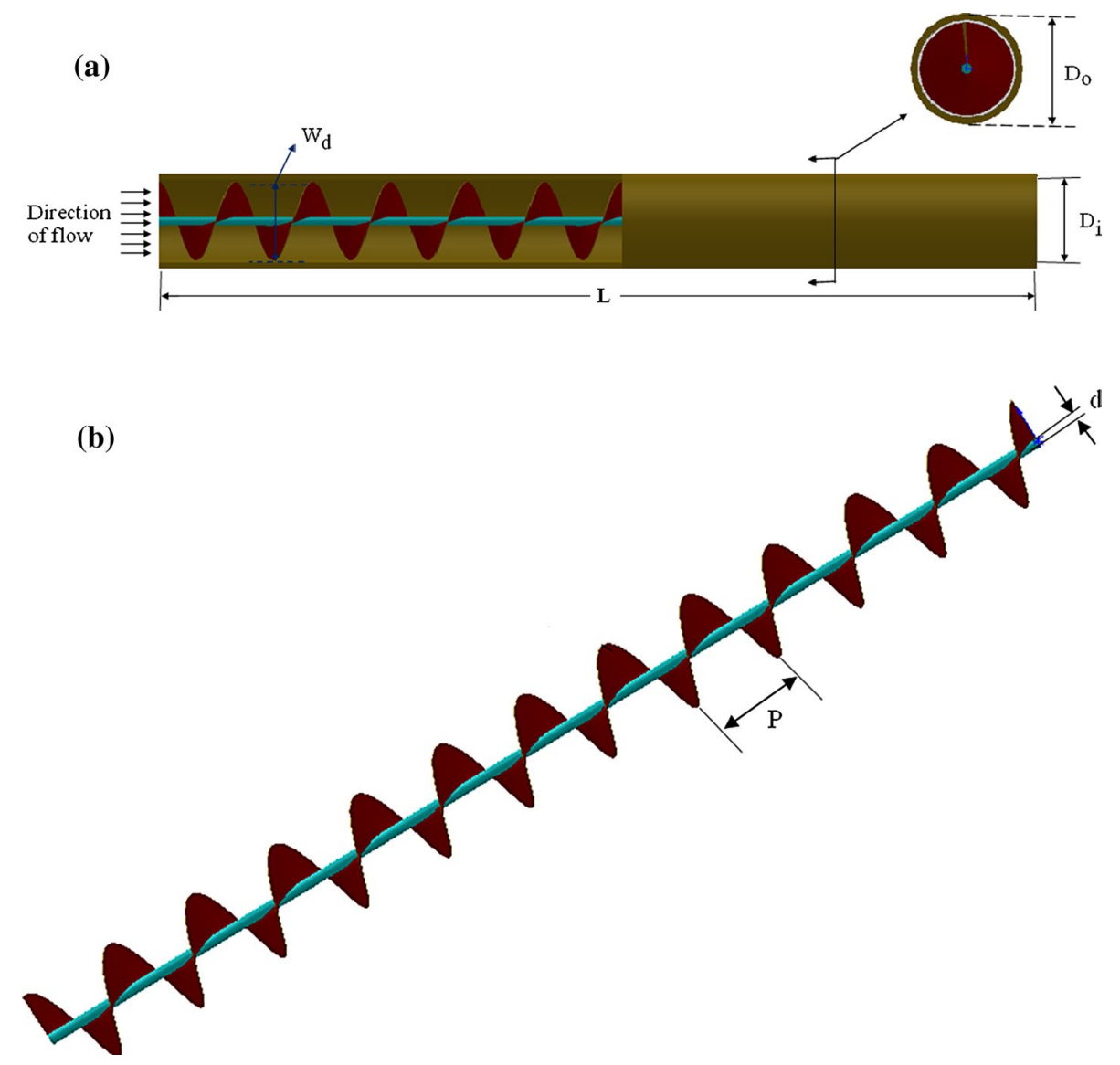

wire (resistance $1.2 \Omega / \mathrm{m}$ ) was used as an electric heater to heat the test section at constant heat flux condition. Nichrome wire was spirally wounded uniformly around the test section. The terminals of the nichrome wire heating coil were connected to the variac transformer. The electrical output power was controlled by a variac transformer to obtain a constant heat flux condition throughout the entire test section. The outer surface of the test section was well insulated to minimize heat leak to the surroundings. The plain tube in the test section was covered with mica sheet to isolate electrically. A layer of glass fibre tape was put on the mica sheet. Nichrome wire (of resistance $1.2 \Omega / \mathrm{m}$ ) was used as an electric heater and was spirally wounded uniformly with spacing of $16 \mathrm{~mm}$ around the tube. Then mica sheet, glass fibre tape, heat insulating tape and asbestos tape were sequentially put over the nichrome wire heater coil to minimize the heat loss

Sixteen K-type thermocouples were tapped along the tube wall for monitoring the local wall temperatures while the bulk air temperatures were measured with the help of RTDs. Data logger was used to record the inlet and outlet bulk fluid temperatures as well as to measure the tube wall temperatures of the test section. The calibrated thermocouples were used to measure the temperatures of the wall as well as the bulk fluid temperature of the test section. The pressure drop across the test section was measured with an inclined U-tube manometer. The heat transfer and pressure drop experiments were carried out individually. The heat transfer experiment was performed under a constant heat flux condition. In contrast, the pressure drop (friction) test was conducted under an isothermal condition without turning on the heater.

The air flow rate was measured by using an orifice meter that was built according to the ASME standard [27] and was calibrated with a hot-wire anemometer to measure the flow velocities across the tube section. The experiments were conducted for the Reynolds number ranging from 7200 to 50,000 .

The uncertainties in the experimental measurements were determined by using the method introduced by Kline and McClintock [28]. The uncertainty calculation method used the calculation of derivatives of the desired variables with respect to the individual experimental quantities, and applied with the known uncertainties. The maximum uncertainties of non-dimensional parameters were found to be $\pm 1.6 \%$ for Reynolds number, $\pm 4 \%$ for Nusselt number, and $\pm 4.2 \%$ for friction factor. 


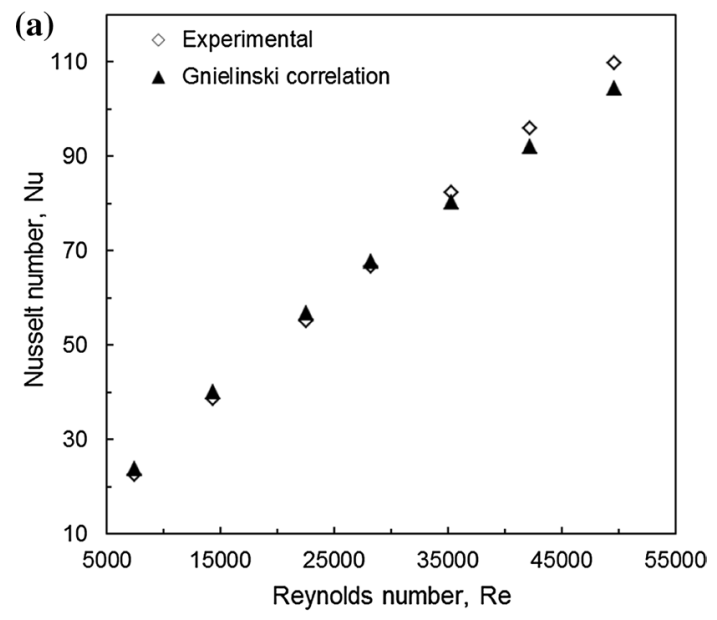

(b)

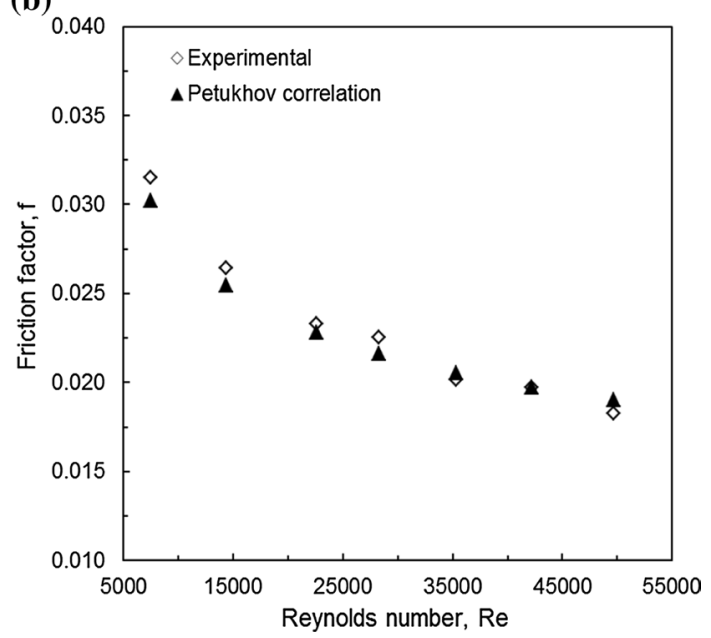

Fig. 3 Validation of the plain tube: a Nusselt number and $\mathbf{b}$ friction factor

\section{Results and discussion}

\subsection{Validation test of the plain tube results}

The results obtained from present experiments on heat transfer and friction factor characteristics of the plain tube were verified in terms of Nusselt number and friction factor. The Nusselt number and friction factor data obtained from the plain tube used in this experiment were validated with those from the proposed correlations by Gnielinski [29] and Petukhov [30] for the Nusselt number and friction factor in Fig. 3a, b, respectively.

Gnielinski [29] correlation as given in Eq. (13) was used to find out the heat transfer in plain tube:

$$
N u=\frac{\left(\frac{f}{8}\right)(\operatorname{Re}-1000) \operatorname{Pr}}{1+12.7\left(\frac{f}{8}\right)^{1 / 2}\left(\operatorname{Pr}^{2 / 3}-1\right)} 3000 \leq \mathrm{Re} \leq 5 \times 10^{6}
$$

and correlation of Petukhov [30] was given in Eq. (14) for calculating friction factor as follows:

$f=(0.790 \ln \mathrm{Re}-1.64)^{-2} \quad 3000 \leq \operatorname{Re} \leq 5 \times 10^{6}$

The comparison between the results of the present plain tube and the correlations of Eqs. (15) and (16) are shown in Fig. 3a, b, respectively. The results obtained from the present plain tube were agreed well with those from the proposed correlations within \pm 5 and $\pm 4 \%$ deviations for the Nusselt number and friction factor, respectively. These results revealed the accuracy of the present experimental facility and the measurement technique.

The correlations obtained from the present plain tube results for the Nusselt number and the friction factor, respectively, were given as follows:

$$
\begin{aligned}
& N u=0.0137 \mathrm{Re}^{0.843} \stackrel{0.33}{\mathrm{Pr}} \\
& f=0.431 \mathrm{Re}^{-0.292}
\end{aligned}
$$

\subsection{Heat transfer characteristics}

Figure $4 \mathrm{a}, \mathrm{b}$ show the relationship between the Nusselt number and the Reynolds number of the helical tape inserts of different twist ratios. It was shown from Fig. 4a that for all cases, the Nusselt number was increased with the increase of Reynolds number. This was attributed to the increase of turbulent intensity as the Reynolds number was increased, which led to an amplification of convective heat transfer. The influence of using the helical tape swirl generators on the heat transfer rate were significant for all the Reynolds numbers. At the comparable Reynolds number, the Nusselt numbers for the tube equipped with helical tape inserts were considerably higher than those of the plain tube. In general, the helical tape inserts generated swirl flow or secondary flow offering a longer flowing path of fluid flow through the tube. The full length helical tape acted as a continuous swirling flow over the entire length of the test tube for: (1) increasing the residence time of the flow, (2) reduction or destruction of the thermal boundary layer and (3) increasing the mixing between the core and the tube wall flows [12]. This swirl flow resulted in the reduction of boundary layer thickness and the increase in flow velocity. The boundary layer separation was occurred due to the radial velocity components of the flow and the rotational/swirl induced by the twisted tape inserts. In addition, the swirl enhanced the flow turbulence intensity, which led to an even better convection heat transfer than the axial flow of the plain tube.

From the experimental results, it could be observed that the heat transfer rate increased with decreasing twist ratio of the tape inserts. It was depicted from Fig. 4a that the Nusselt number for a given Reynolds number was higher 

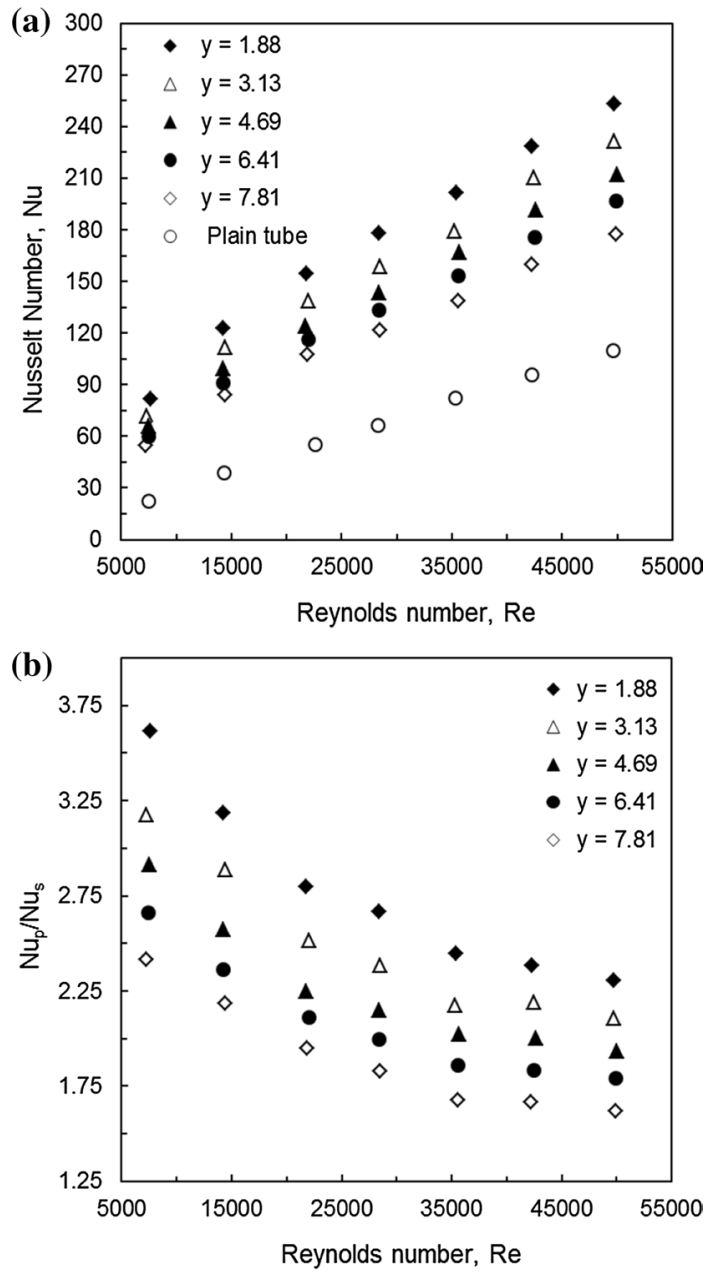

Fig. 4 Relationship between the Nusselt number and Reynolds number: $\mathbf{a} \mathrm{Nu}$ and $\mathbf{b} \mathrm{Nu}_{\mathrm{p}} / \mathrm{Nu}_{\mathrm{s}}$

at the lower twist ratio of the tape inserts which indicated the enhanced heat transfer rate. This could be explained by the fact that at lower twist ratio, stronger swirl intensity was generated, which led to more efficient interruption of boundary layer along the flow path. Over the range studied, the helical tape insert with the smaller twist ratio provided the higher heat transfer rate than those of the tube with the higher ones.

Eiamsa-ard and Promvonge [19] showed that the maximum mean Nusselt number for the full-length helical tape with centered-rod increased by $160 \%$ in comparison to that of the plain tube for the Reynolds number ranging between 2300 and 8800. In a further study they [20] showed that the average Nusselt number of using the loose-fit helical tape with corerod was found to be increased up to $230 \%$ over the corresponding plain tube. Sivashanmugam and Suresh [22] showed that the Nusselt number decreased nearly 30-40 \% with the increase of twist ratio (1.95-4.89) for the full-length helical screw inserts compared to the plain tube for all the Reynolds number. Hasan and Sumathy [24] showed that the helical tape inserts could enhance the heat transfer rate by 1.15-1.7 times compared to that of the plain tube with a lower twist ratio (11) for the low Reynolds number ranging from 8050 to 13,600 .

The effectiveness of heat transfer enhancement in the tube equipped with helical tapes compared to those of the plain tube, in terms of Nusselt number ratio $\left(N u_{p} / N u_{s}\right)$ is presented in Fig. 4(b). From Fig. 4(b), it was apparent that the Nussselt number ratio tended to decrease with increasing Reynolds number. This was because of the influence of helical tape insert on heat transfer enhancement was less significant for increasing Reynolds number. It was observed from Fig. 4b that the Nusselt number ratio of all the investigated cases were consistently higher than the unity. This implied the beneficial gain for heat transfer enhancement of using the helical tape inserts over the plain tube. According to the experimental results, the Nusselt numbers of the tube with helical tape inserts were found to be 60-260 \% higher than those of the plain tube values.

\subsection{Fluid flow characteristics}

The effect of the twist ratio of the tube fitted with the helical tape inserts on friction factor characteristics at different Reynolds number is exhibited in Fig. 5a. It could be shown from Fig. 5a that the friction factor was in the similar trend both for the plain tube and the tube with inserts. It could be clearly depicted from Fig. 5a that the friction factor continue decreased with increasing Reynolds number. As expected from Fig. 5a, the friction factors obtained from the tube with helical tape inserts were significantly higher than those of the plain tube. This was because of the flow blockage, larger contact surface areas and the dissipation of dynamic pressure of the fluid at high viscosity loss near the tube wall. Moreover, the pressure loss had a high possibility to occur by the interaction of the pressure forces with inertial forces in the boundary layer.

Furthermore, it could be shown from Fig. 5a that the friction factor tended was increased with decreasing of the twist ratio and vice versa, which was comparable with the findings of Sivashanmugam and Suresh [22]. They showed that the friction factor decreased with the increase of twist ratio from 1.89 to 4.89 by $40-45 \%$ for the full-length helical screw inserts. This could be attributed to the use of helical tape insert with lower twist ratio, which caused the stronger swirl flow or turbulence flow and long residence time in the tube.

Figure $5 \mathrm{~b}$ depicts the variation of friction factor ratio $\left(f_{p} / f_{s}\right)$ with Reynolds number for different twist ratios. It was shown from Fig. $5 b$ that the friction factor ratio tended to decrease with raising the Reynolds number for all the investigated cases. Over the range investigated, the friction factors for the tube fitted with the helical tape inserts were found to be 75-285\% higher compared to those of the plain tube values. 

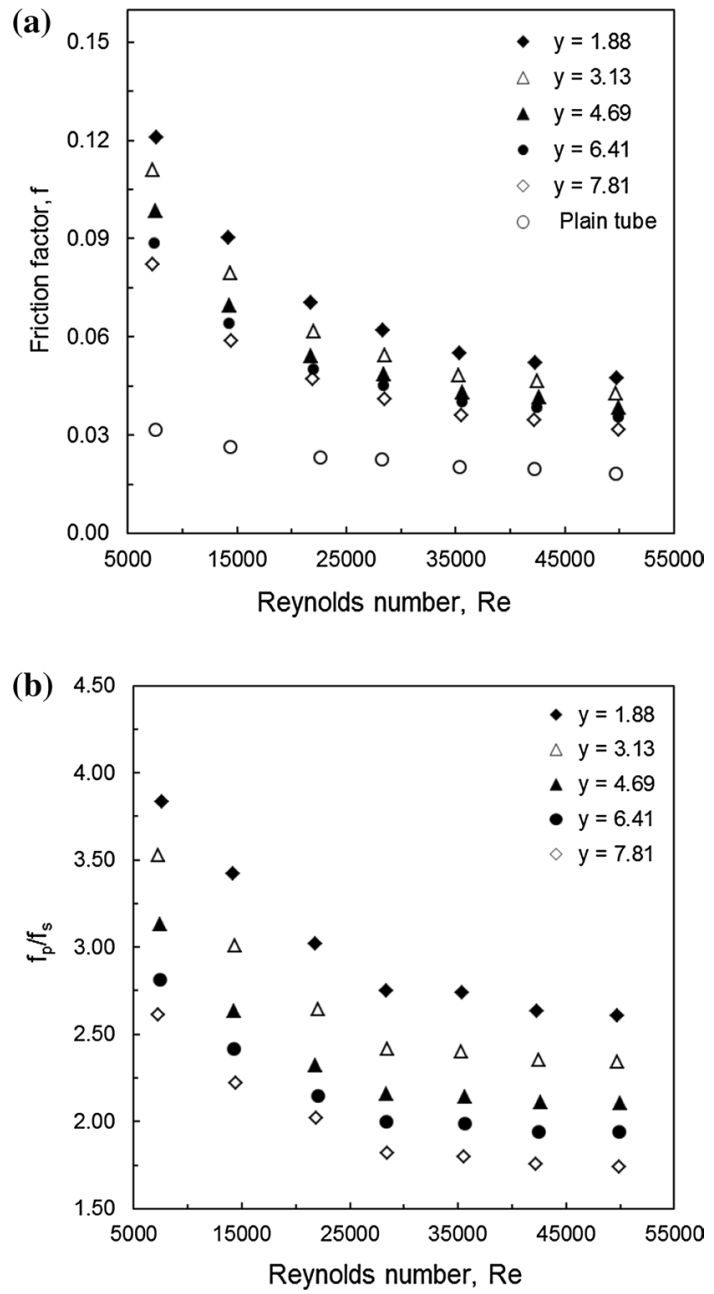

Fig. 5 Relationship between the friction factor and Reynolds number: $\mathbf{a}$ f and $\mathbf{b} \mathrm{f}_{\mathrm{p}} / \mathrm{f}_{\mathrm{s}}$

\subsection{Performance evaluation}

In order to appraise the heat transfer augmentation performance of the tube fitted with five different helical tape inserts, a constant blower power comparison was made. Based on constant blower power, the performance evaluation criteria could be written as:

$(\dot{V} \Delta P)_{s}=(\dot{V} \Delta P)_{p}$

From the relationship between the friction factor and the Reynolds number, it could be expressed as:

$$
\begin{aligned}
& \left(f \operatorname{Re}^{3}\right)_{s}=\left(f \operatorname{Re}^{3}\right)_{p} \\
& \operatorname{Re}_{s}=\operatorname{Re}_{p}\left(\frac{f_{p}}{f_{s}}\right)^{\frac{1}{3}}
\end{aligned}
$$

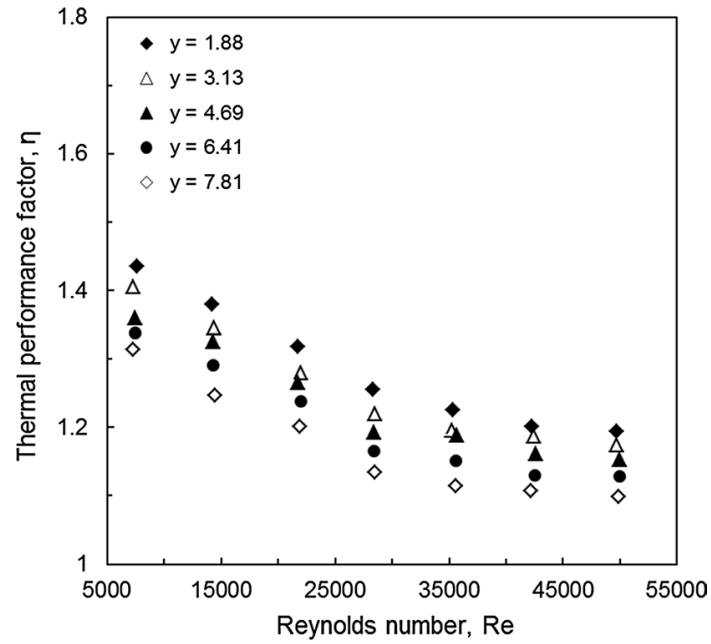

Fig. 6 Relationship between the thermal performance factor and Reynolds number

Applying Eqs. (16), (19) and (23), the Reynolds number $\left(R e_{s}\right)$ for the plain tube could be expressed as the function of Reynolds number for the tube fitted with helical tape $\left(R e_{p}\right)$ :

$\operatorname{Re}_{s}=1.364515 .\left\{0.0458 y^{3}-0.5552 y^{2}+1.0854 y+10.473\right\}^{0.369273}$.

$$
\operatorname{Re}_{p}^{\left\{-0.000295 y^{3}+0.004136 y^{2}-0.01599 y+0.939616\right\}}
$$

The thermal performance factor $(\eta)$ is defined as the ratio of the Nusselt number ratio to the friction factor ratio at the same blower power. The performance of the augmented tube was evaluated relatively to the plain tube at an identical blower power, the correlation proposed by Bhuiya et al. [17, 31-35], Wongcharee and Eiamsa-ard [15] and Shabanian et al. [36] in terms of thermal performance factor which could be expressed as:

$\eta=\frac{\frac{N u_{p}}{N u_{s}}}{\left(\frac{f_{p}}{f_{s}}\right)^{\frac{1}{3}}}$

The variation of thermal performance factor with the Reynolds number is represented in Fig. 6. The comparative data revealed that the thermal performance factor decreased with increasing Reynolds number as well as twist ratios. The performance factors were consistently larger than the unity which revealed the advantage of the double twisted tapes in viewpoint of energy saving. The performance factor above unity indicated that the effect of heat transfer enhancement due to the turbulator was more dominant than the effect of rising friction and vice versa. It could be expressed from Fig. 6 that the heat transfer augmentation was effective for all the Reynolds number while the heat transfer augmentation rate was comparatively higher 


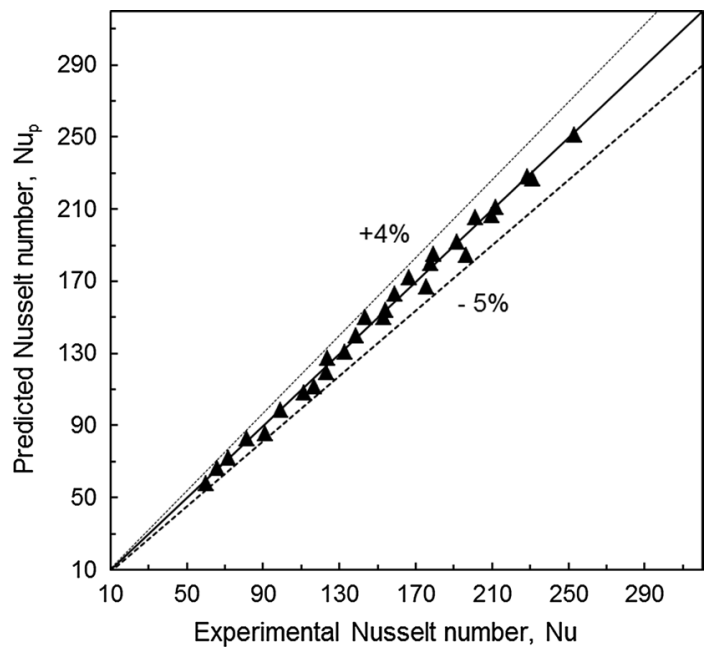

Fig. 7 Comparison between the predicted and experimental Nusselt number

at lower Reynolds number and tended to decrease with the increase of Reynolds number. This might be due to the increase of friction forces as well as pressure drops. The heat transfer performance was obtained for the tube with helical tape inserts of different twist ratios, and found to be $10-44 \%$ higher compared to the plain tube values.

\subsection{Correlations for prediction of heat transfer, friction factor and thermal performance factor}

The correlations were developed for the turbulent flow region applicable for a wide range of Reynolds number from 7200 to 50,000 and twist ratios ranging from 1.88 to 7.81 . The correlations developed for the Nusselt number, friction factor and thermal performance factor in the present experimental results of the tube fitted with helical tapes could be written in terms of twist ratio $(y)$, Reynolds number $(R e)$ and Prandtl number (Pr) in Eqs. (22), (23) and (24), respectively.

$$
\begin{aligned}
N u_{p}= & \left\{0.0005 y^{3}-0.0015 y^{2}-0.057 y+0.5747\right\} \\
& \operatorname{Re}_{p}^{\left\{-0.0004 y^{3}+0.0049 y^{2}-0.0125 y+0.6013\right\}} \cdot \operatorname{Pr}^{0.33}
\end{aligned}
$$

$$
\begin{aligned}
f_{p}= & \left\{0.0458 y^{3}-0.5552 y^{2}+1.0854 y+10.473\right\} \\
& \operatorname{Re}_{p}^{\left\{-0.0008 y^{3}+0.0112 y^{2}-0.0433 y-0.4555\right\}}
\end{aligned}
$$

$$
\begin{aligned}
\eta_{p}= & 41.176 . C . C_{1}^{-0.6802} \\
& . \operatorname{Re}_{p}^{\left\{0.000144 y^{3}-0.002718 y^{2}+0.016953 y-0.130488\right\}}
\end{aligned}
$$

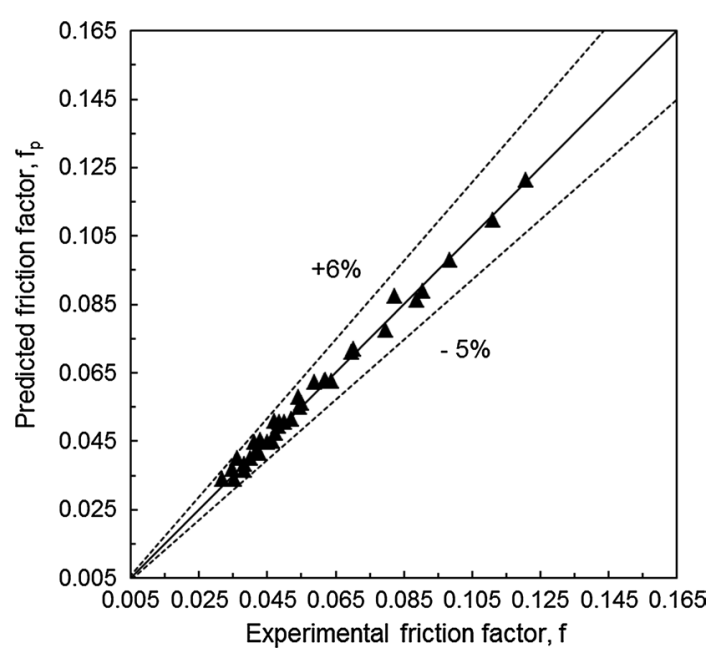

Fig. 8 Comparison between the predicted and experimental friction factor

where $C=\left\{0.0005 y^{3}-0.0015 y^{2}-0.057 y+0.5747\right\}$ and $C_{1}=\left\{0.0458 y^{3}-0.5552 y^{2}+1.0854 y+10.473\right\} \quad$ The Nusselt number, friction factor and thermal performance factor values predicted from the correlation Eqs. (22), (23) and (24) were compared with the experimental values, and the comparisons are shown in Figs. 7, 8 and 9, respectively. From Figs. 7, 8 and 9, it could be noted that the Nusselt number, friction factor and thermal performance factor $(\eta)$ values obtained from the predicted correlation Eqs. (22), (23) and (24) agreed well with the experimental values for all the investigated cases within +4 to $-5 \%,+6$ to $-5 \%$, and $\pm 2 \%$ deviations of the proposed correlations, respectiv ely.

\section{Conclusion}

An experimental study was conducted to investigate the air flow friction and heat transfer characteristics in a circular tube fitted with helical tape inserts of different twist ratios $(y=1.88,3.13,4.69,6.41$ and 7.81$)$ for turbulent flow regime, $R e=7200$ to 50,000 . The use of helical tape inserts provided significant augmentation of heat transfer by causing a high pressure drop increase. Based on the experimental results, key findings of this study could be summarized as follows:

- The helical tape offered a significant enhancement of heat transfer, friction factor as well as thermal performance factor $(\eta)$ compared to the plain tube values.

- In general observations, it was found that the heat transfer, friction factor and thermal performance factor $(\eta)$ increased with decreasing twist ratio. Furthermore, the Nusselt number 


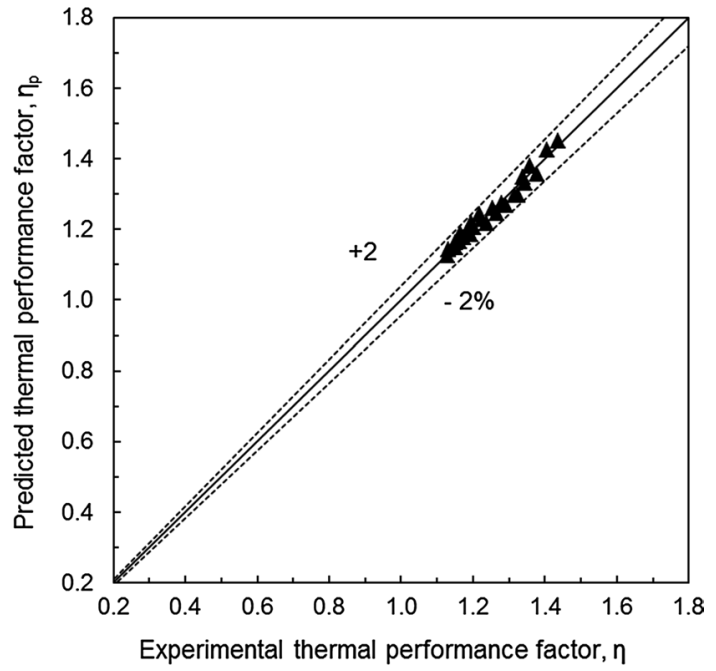

Fig. 9 Comparison between the predicted and experimental thermal performance factor

increased with increasing Reynolds number while the opposite trends were found for the case of friction factor and thermal performance factor $(\eta)$.

- The thermal performance factor $(\eta)$ for all the cases was more than one, which indicated that the effect of heat transfer enhancement due to the enhancing tool was more dominant than the effect of the rising friction factor and vice versa.

- The Nusselt number and friction factor for the tube with helical tape inserts was obtained 60-260\% and 75-285\% higher than those of the plain tube values at the comparable Reynolds number, respectively.

- The thermal performance factor $(\eta)$ in the tubes equipped with helical tapes at constant blower power was achieved to be around 1.1-1.44.

The empirical correlations developed in the present study, provided the correlative results of the Nusselt number, friction factor and thermal enhancement efficiency. The predicted data obtained from the developed correlations were in good agreement with the experimental data within +4 to $-5,+6$ to -5 , and $\pm 2 \%$, for Nusselt number, friction factor and thermal performance factor $(\eta)$, respectively.

Acknowledgements The authors would like to gratefully acknowledge the Chittagong University of Engineering and Technology (CUET) for their support in this research.

\section{References}

1. Bergles AE (2002) ExHFT for fourth generation heat transfer technology. Exp Therm Fluid Sci 26:335-344
2. Dewan A, Mahanta P, Raju KS, Kumar PS (2004) Review of passive heat transfer augmentation techniques. Proc Inst Mech Eng A J Power Energy 218:509-527

3. Sarkar MR, Islam MZ, Islam M (2005) Heat transfer in turbulent flow through tube with wire-coil inserts. J Enhanced Heat Transf $12: 385-394$

4. Naphon P (2006) Effect of coil-wire insert on heat transfer enhancement and pressure drop of the horizontal concentric tubes. Int Commun Heat Mass Transf 33:753-763

5. Promvonge $P$ (2008) Thermal enhancement in a round tube with snail entry and coiled-wire inserts. Int Commun Heat Mass Transf 35:623-629

6. Gunes S, Ozceyhan V, Buyukalaca O (2010) Heat transfer enhancement in a tube with equilateral triangle cross sectioned coiled wire inserts. Exp Therm Fluid Sci 34:684-691

7. Promvonge $P(2008)$ Thermal augmentation in circular tube with twisted tape and wire coil turbulators. Energy Convers Manag 49:2949-2955

8. Eiamsa-ard S, Thianpong C, Promvonge P (2006) Experimental investigation of heat transfer and flow friction in a circular tube fitted with regularly spaced twisted tape elements. Int Commun Heat Mass Transf 33:1225-1233

9. Naphon P (2006) Heat transfer and pressure drop in the horizontal double pipes with and without twisted tape insert. Int Commun Heat Mass Transf 33:166-175

10. Patil S, Vijaybabu P (2012) Heat transfer enhancement through a square duct fitted with twisted tape inserts. Heat Mass Transf 48:1803-1811

11. Zohir A (2012) Turbulent heat transfer characteristics and pressure drop in swirling flow at upstream and downstream of an abrupt expansion. Heat Mass Transf 48:529-539

12. Eiamsa-ard S, Thianpong C, Eiamsa-ard P, Promvonge P (2009) Convective heat transfer in a circular tube with short-length twisted tape insert. Int Commun Heat Mass Transf 36:365-371

13. Eiamsa-ard S, Thianpong C, Eiamsa-ard P (2010) Turbulent heat transfer enhancement by counter/co-swirling flow in a tube fitted with twin twisted tapes. Exp Therm Fluid Sci 34:53-62

14. Eiamsa-ard S, Promvonge P (2010) Performance assessment in a heat exchanger tube with alternate clockwise and counter-clockwise twisted-tape inserts. Int J Heat Mass Transf 53:1364-1372

15. Wongcharee K, Eiamsa-ard S (2011) Enhancement of heat transfer using $\mathrm{CuO} /$ water nanofluid and twisted tape with alternate axis. Int Commun Heat Mass Transf 38:742-748

16. Wongcharee K, Eiamsa-ard S (2011) Heat transfer enhancement by twisted tapes with alternate-axes and triangular, rectangular and trapezoidal wings. Chem Eng Process 50:211-219

17. Bhuiya MMK, Chowdhury MSU, Islam M, Ahamed JU, Khan MJH, Sarker MRI, Saha M (2012) Heat transfer performance evaluation for turbulent flow through a tube with twisted wire brush inserts. Int Commun Heat Mass Transf 39:1505-1512

18. Eiamsa-ard S, Yongsiri K, Nanan K, Thianpong C (2012) Heat transfer augmentation by helically twisted tapes as swirl and turbulence promoters. Chem Eng Process 60:42-48

19. Eiamsa-ard S, Promvonge P (2005) Enhancement of heat transfer in a tube with regularly-spaced helical tape swirl generators. Sol Energy 78:483-494

20. Eiamsa-ard S, Promvonge P (2007) Heat transfer characteristics in a tube fitted with helical screw-tape with/without core-rod inserts. Int Commun Heat Mass Transf 34:176-185

21. Sivashanmugam P, Suresh S (2007) Experimental studies on heat transfer and friction factor characteristics of turbulent flow through a circular tube fitted with helical screw-tape inserts. Chem Eng Process 46:1292-1298

22. Sivashanmugam P, Suresh S (2007) Experimental studies on heat transfer and friction factor characteristics of turbulent flow 
through a circular tube fitted with regularly spaced helical screwtape inserts. Appl Therm Eng 27:1311-1319

23. Sivashanmugam P, Nagarajan P, Suresh S (2008) Experimental studies on heat transfer and friction factor characteristics of turbulent flow through a circular tube fitted with right and left helical screw-tape inserts. Chem Eng Commun 195:977-987

24. Hasan M, Sumathy K (2009) Study on the potential use of helical swirl generators in enhancing the thermal performance of solar air heaters. Int J Ambient Energy 30:207-216

25. Suresh S, Venkitaraj KP, Selvakumar P (2011) Comparative study on thermal performance of helical screw tape inserts in laminar flow using $\mathrm{Al} 2 \mathrm{O} 3 /$ water and $\mathrm{CuO} /$ water nanofluids. Superlattices Microstruct 49:608-622

26. Ower E, Pankhurst RC (1977) Measurement of air flow, 5th edn (in SI units) Pergamon Press

27. Standard A (1984) Measurement of fluid flow in pipes using orifice, nozzle and venturiASME MFC-3M United Engineering Center 345 East 47th Street, New York, pp 1-56

28. Kline SJ, McClintock F (1953) Describing uncertainties in single-sample experiments. Mech Eng 75:3-8

29. Gnielinski V (1975) New equations for heat and mass transfer in the turbulent flow in pipes and channels. NASA STI/recon technical report A 75: 22028

30. Petukhov B (1970) Heat transfer in turbulent pipe flow with variable physical properties. In: Irvine T, Hartnett J (eds) Advances in heat transfer. Academic Press, New York, pp 504-564

31. Bhuiya MMK, Chowdhury MSU, Shahabuddin M, Saha M, Memon LA (2013) Thermal characteristics in a heat exchanger tube fitted with triple twisted tape inserts. Int Commun Heat Mass Transf 48:124-132. doi:10.1016/j. icheatmasstransfer.2013.08.024

32. Bhuiya MMK, Sayem ASM, Islam M, Chowdhury MSU, Shahabuddin M (2014) Performance assessment in a heat exchanger tube fitted with double counter twisted tape inserts. Int Commun Heat Mass Transf 50:25-33. doi:10.1016/j. icheatmasstransfer.2013.11.005

33. Bhuiya MMK, Ahamed JU, Chowdhury MSU, Sarkar MAR, Salam B, Saidur R, Masjuki HH, Kalam MA (2012) Heat transfer enhancement and development of correlation for turbulent flow through a tube with triple helical tape inserts. Int Commun Heat Mass Transf 39:94-101. doi:10.1016/j. icheatmasstransfer.2011.09.007

34. Bhuiya MMK, Chowdhury MSU, Ahamed JU, Khan MJH, Sarkar MAR, Kalam MA, Masjuki HH, Shahabuddin M (2012) Heat transfer performance for turbulent flow through a tube using double helical tape inserts. Int Commun Heat Mass Transf 39:818-825. doi:10.1016/j.icheatmasstransfer.2012.04.006

35. Bhuiya MMK, Chowdhury MSU, Saha M, Islam MT (2013) Heat transfer and friction factor characteristics in turbulent flow through a tube fitted with perforated twisted tape inserts. Int Commun Heat Mass Transf 46:49-57. doi:10.1016/j. icheatmasstransfer.2013.05.012

36. Shabanian SR, Rahimi M, Shahhosseini M, Alsairafi AA (2011) CFD and experimental studies on heat transfer enhancement in an air cooler equipped with different tube inserts. Int Commun Heat Mass Transf 38:383-390 